\title{
Correlation of liver-to-spleen ratio, lung CT scores, clinical, and laboratory findings of COVID-19 patients with two consecutive CT scans
}

\author{
Ezgi Guler ${ }^{1}$ (1) Nalan Gulsen Unal ${ }^{2} \cdot$ Akin Cinkooglu $^{1} \cdot$ Recep Savas $^{1} \cdot$ Timur Kose $^{3} \cdot$ Husnu Pullukcu ${ }^{4}$. \\ Mustafa Harman ${ }^{1} \cdot$ Nevra Z. Elmas ${ }^{1} \cdot$ Nikhil H. Ramaiya $^{5} \cdot$ Ahmet Omer Ozutemiz $^{2}$
}

Received: 5 July 2020 / Revised: 19 September 2020 / Accepted: 30 September 2020 / Published online: 13 October 2020

○) Springer Science+Business Media, LLC, part of Springer Nature 2020

\begin{abstract}
Purpose Given the lack of information about abdominal imaging findings and correlation with clinical features of COVID19 , we aimed to evaluate the changes in hepatic attenuation during the course of disease. Our aim was to correlate the liverto-spleen ratio (L/S), clinical, laboratory findings, and lung CT scores of patients with COVID-19 who had two consecutive chest CTs.

Methods A retrospective search was performed between March 1, 2020 and April 26, 2020 to identify patients who had positive RT-PCR tests and two unenhanced chest CTs. Scans that were obtained at hospital admission and follow-up were reviewed to assess L/S and lung CT scores. Patients were divided into two groups based on lung CT scores (non-progressive vs progressive). Patient demographics, laboratory findings, length of hospital stay, and survival were noted from electronic medical records.

Results Twenty patients in the progressive group and 7 patients in the non-progressive group were identified. The mean $\mathrm{L} / \mathrm{S}$ of the progressive group $(1.13 \pm 0.3)$ was lower than that of the non-progressive group $(1.21 \pm 0.29)$ at hospital admission but there was no significant difference between the two groups $(p=0.547)$. L/S at follow-up was significantly different between the groups as the mean $\mathrm{L} / \mathrm{S}$ values of the progressive and non-progressive groups were $1.02 \pm 0.23$ and $1.25 \pm 0.29$, respectively $(p=0.009)$. L/S was negatively correlated with AST and ALT $(r=-0.46, p=0.016$ and $r=-0.534, p=0.004$, respectively). There were significant differences between the two groups in terms of WBC, neutrophil, lymphocyte, monocyte, and platelet counts that were obtained at hospital admission. Length of hospital stay was significantly longer in patients in the progressive group $(p=0.035)$.

Conclusions Decrease in L/S may be observed in patients with elevated lung CT scores at follow-up. WBC, neutrophil, lymphocyte, monocyte, and platelet counts at hospital admission may predict the progression of COVID-19.
\end{abstract}

Keywords Coronavirus $\cdot$ Multidetector computed tomography $\cdot$ Laboratory $\cdot$ Thorax $\cdot$ Liver

Ezgi Guler

gulerezgi@yahoo.com

1 Department of Radiology, Faculty of Medicine, Ege University, Bornova, Izmir 35100, Turkey

2 Division of Gastroenterology, Department of Internal Medicine, Faculty of Medicine, Ege University, Izmir, Turkey

3 Department of Biostatistics, Faculty of Medicine, Ege University, Izmir, Turkey

4 Department of Infectious Diseases and Clinical Microbiology, Faculty of Medicine, Ege University, Izmir, Turkey

5 Department of Radiology, University Hospitals Cleveland Medical Center, Cleveland, USA

\section{Introduction}

Coronavirus disease 2019 (COVID-19), which is caused by the severe acute respiratory syndrome coronavirus 2 (SARSCoV-2) has been a threat to global public health [1]. Reverse transcription-polymerase chain reaction (RT-PCR) test is the gold standard for the molecular diagnosis of the disease [2]. Although it is a highly specific test, in clinical use it shows a variable sensitivity, which arises the need of other tools to support the diagnosis. Since chest computed tomography (CT) is widely available and can contribute to fast pneumonia diagnosis, it plays an important role in the diagnosis and management of COVID-19 patients [2-5]. 
COVID-19 demonstrates a wide clinical spectrum ranging from asymptomatic infection to severe pneumonia with acute respiratory distress syndrome, multiple organ failure, and death, with many patients being hospitalized [6-8]. Older age, comorbidities including hypertension, diabetes, cardiovascular disease, respiratory disease, and laboratory examinations such as white blood cells (WBC), aspartate aminotransferase (AST), creatinine, lactate dehydrogenase $(\mathrm{LDH})$, and d-dimer have been reported to imply the progression of COVID-19 $[9,10]$. Chest CT findings have been shown to be associated with severe or critical COVID-19 pneumonia as well as with the different stages of the disease $[11,12]$. Although the involvement of the respiratory system is common, liver injury may occur especially in patients with severe COVID-19 [13].

Changes of hepatic density on unenhanced CT scans can occur in diffuse liver diseases, whether as a decrease in steatosis or an increase in hemochromatosis [14, 15]. Other entities that may alter hepatic density on CT include drug-induced toxicity, acute hepatitis, acute toxic hepatic injury, cirrhosis, and radiation-induced injury [15]. It has been reported that unenhanced CT scans demonstrate diffuse hypoattenuating areas in the liver of patients with viral acute liver failure [16]. Liver-to-spleen ratio (L/S) on unenhanced CT has been used to discriminate hepatic steatosis [17]. Thus, L/S may be helpful in the evaluation of liver injury as it reflects the changes of hepatic attenuation. Given the lack of information in the literature for the assessment of abdominal imaging findings in COVID-19 patients, which may be related to the limited evaluation of the upper abdomen on unenhanced chest CT scans, we aimed to investigate the changes in L/S during the course of disease. The purpose of this study is to correlate the L/S, clinical, laboratory findings, and lung CT scores of COVID-19 patients who had two consecutive chest CT scans.

\section{Materials and methods}

\section{Patients}

This retrospective study was approved by our institutional review board and the requirement for informed consent was waived. A database search between March 1, 2020 and April 26, 2020 was performed to identify patients with COVID19 and who had chest CT scans. Inclusion criteria were as follows,

1. adult patients (age $\geq 18$ years),

2. patients who had positive RT-PCR tests for COVID-19,

3. patients who had two consecutive unenhanced chest CTs (obtained at hospital admission and follow-up).
Exclusion criteria were as follows,

1. patients who had positive RT-PCR tests but did not have chest CTs,

2. patients who had only one chest CT scan, and

3. patients who had only contrast-enhanced chest CTs.

\section{Clinical and laboratory data}

The electronic medical records were reviewed to note the laboratory examinations obtained within 1-day interval time of the corresponding dates of the first and second chest CT scans. Laboratory examinations including blood AST (normal limits, $<35 \mathrm{U} / \mathrm{L}$ ), alanine aminotransferase (ALT) (normal limits, $<45 \mathrm{U} / \mathrm{L}$ ), alkaline phosphatase (ALP) (35-104 U/L), gamma-glutamyltransferase (GGT) (normal limits, $<38 \mathrm{U} / \mathrm{L})$, total bilirubin $(0.1-1 \mathrm{mg} / \mathrm{dL})$, creatinine $(0.6-1.1 \mathrm{mg} / \mathrm{dL})$, C-reactive protein $(\mathrm{CRP})(0-5 \mathrm{mg} / \mathrm{L})$, LDH (normal limits, $<225 \mathrm{IU} / \mathrm{L})$, d-dimer $(<550 \mu \mathrm{g} / \mathrm{L}$ FEU), WBC $\left(4.5-11 \times 10^{3} / \mu \mathrm{L}\right)$, neutrophil $\left(2.02-7.46 \times 10^{3} /\right.$ $\mu \mathrm{L})$, lymphocyte $\left(1-3.38 \times 10^{3} / \mu \mathrm{L}\right)$, monocyte $\left(0-0.8 \times 10^{3} /\right.$ $\mu \mathrm{L})$, hemoglobin $(\mathrm{Hb})(11.7-16 \mathrm{~g} / \mathrm{dL})$, and platelet count $\left(150-450 \times 10^{3} / \mu \mathrm{L}\right)$ were recorded. Neutrophil/lymphocyte ratio was calculated. Comorbidities of the patients including diabetes, hypertension, chronic renal failure, and malignancy were noted. The treatment, length of hospital stay and survival of the patients were recorded. Empiric treatment of COVID-19 was given according to the guidelines of the National Ministry of Health. The agents including hydroxychloroquine, azithromycin, other antibiotics, oseltamivir, and favipiravir were used in the treatment acccording to the severity of pneumonia [18].

\section{Imaging studies and analysis}

All CT scans were performed using a 160-slice-CT scanner (Aquilion Prime, Canon Medical Systems, Tochigi, Japan). The axial images were acquired craniocaudally at shallow inspiration and included the body part extending from the thoracic inlet to upper abdomen (including the upper poles to midportion of the kidneys). High-resolution CT of the chest was obtained by using the following parameters; 120 $\mathrm{kVp}, 100-200 \mathrm{~mA}, 80 \times 0.5 \mathrm{~mm}$ collimation and reconstructed at $0.5 \mathrm{~mm}$ slice thickness with a sharp reconstruction kernel. All of the patients underwent CT scans without contrast agent administration. CT images were reviewed in consensus by two thoracic radiologists (A.C and R.S). CT scores were assigned for the first scan that was obtained at hospital admission and follow-up CT scan of each patient to evaluate the extension of the lung involvement. A chest CT scoring system was used in which each lobe was given a score that was based on the following: score 0 , no involvement; score 1, less than 5\% involvement; score 2, 5-25\% 
involvement; score 3, 26-49\% involvement; score 4, 50-75\% involvement; and score 5, greater than $75 \%$ involvement of the lobe. According to this scoring system, the minimum and maximum values of lung CT scores were 0 and 25, respectively [19-21]. Patients were divided into two groups based on the lung CT scores as follows, non-progressive group: patients with decreased or stable CT scores on the follow-up CT scan and progressive group: patients with increased CT scores on the follow-up CT scan.

Two abdominal radiologists in consensus (E.G and N.Z.E) reviewed the upper abdominal parts that were included in the chest CT scans and calculated the L/S. In this study, L/S was obtained from two consecutive unenhanced chest CT scans of each COVID-19 patient to assess if a change occurred in hepatic density during the course of disease. Hepatic attenuation values were calculated by placing two regions of interest (ROI) greater than $100 \mathrm{~mm}^{2}$ in area, in the right liver lobe anterioposteriorly and one ROI in the left liver lobe. Splenic attenuation was obtained by placing one ROI, greater than $100 \mathrm{~mm}^{2}$ in area (Fig. 1). L/S was calculated by taking the average Hounsfield unit (HU) measurement of both liver lobe ROIs and dividing it by the spleen $\mathrm{HU}$ value [22]. Attempts were made to place ROIs in the exact location as possible in both CT scans.

\section{Statistical analysis}

Statistical analyses were performed by using IBM SPSS Statistics for Windows, Version 25.0. (IBM Corp. Released 2017. Armonk, NY) and R software, version 3.5.2, package:

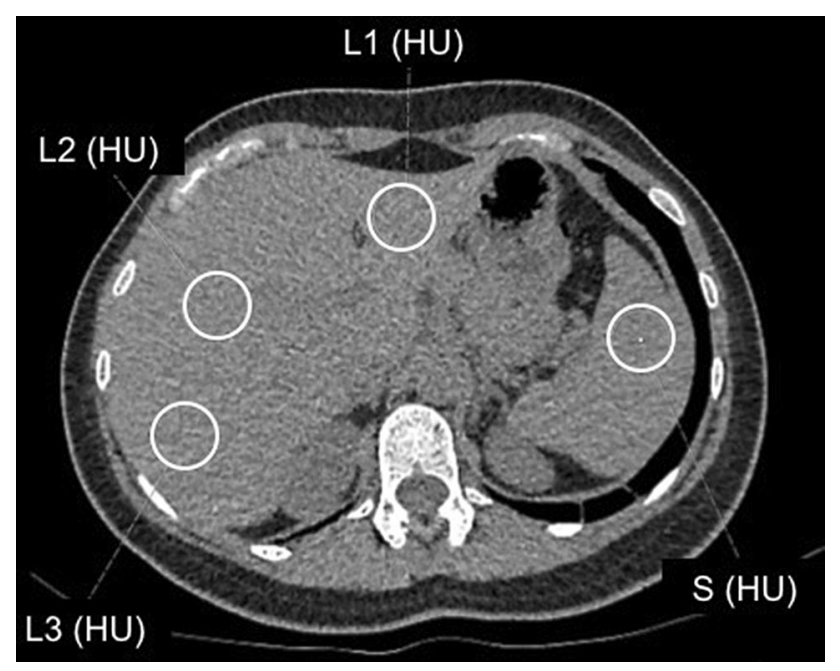

Fig. 1 29-year-old woman with COVID-19. Hepatic attenuation values were calculated by placing one ROI greater than $100 \mathrm{~mm}^{2}$ in area in the left liver lobe (L1), and two ROIs, in the right liver lobe (L2 and L3). Splenic attenuation was obtained by placing one ROI, greater than $100 \mathrm{~mm}^{2}$ in area (S). Liver-to-spleen ratio was calculated as $[(\mathrm{L} 1+\mathrm{L} 2+\mathrm{L} 3) / 3] / \mathrm{S}$
nparLD (R Foundation for Statistical Computing, Vienna, Austria; https://r-project.org).

Normally distributed continuous variables were displayed as mean \pm standard deviation, non-normally distributed continuous variables were displayed as median (minimum-maximum). Repeated measures ANOVA was used for normally distributed variables. When an interaction (interaction represents that the changes of parameters obtained at hospital admission and follow-up were different between the two groups) was found to be significant, paired $t$-test, two independent samples $t$-test, and analysis of covariance were performed. For the evaluation of non-normally distributed variables, the Brunner and Langer method (F1-LD-F1 model) was used. When an interaction was found to be significant, Mann-Whitney U test and Wilcoxon test were performed. Receiver Operating Characteristic (ROC) analysis was used for the assessment of the laboratory values obtained at the time of the first chest CT to predict the changes in the CT scores. Categorical variables were compared between the two groups of patients using the chi-square test and Fisher's exact test. Spearman's Rho analysis was used to evaluate the relationship between $\mathrm{L} / \mathrm{S}$ and liver function tests.

\section{Results}

\section{Clinical and laboratory findings}

Out of consecutive 408 patients who had positive RT-PCR tests, a total of 27 patients who met the inclusion criteria were identified. The flowchart of the study is shown in Fig. 2. There were 7 patients [ 4 men, 3 women; median age: 41 years (29-65 years)] in the non-progressive group and 20 patients [ 8 men, 12 women; median age: 57 years (23-81) years] in the progressive group. Table 1 demonstrates the clinical characteristics of the two groups of patients.

Three (42.8\%) patients in the non-progressive group and $11(55 \%)$ patients in the progressive group had comorbidites. Six $(85.7 \%)$ patients in the non-progressive group and 18 (90\%) patients in the progressive group received hydroxychloroquine therapy. Nine (45\%) patients in the progressive group had favipiravir treatment while it was started in 1 (14.3\%) patient in the non-progressive group. No significant differences of comorbidities and treatment were found between the two groups of patients $(p>0.05)$.

Patients in the progressive group had a significantly longer hospital stay than the patients in the non-progressive group ( $p=0.035)$. Six $(30 \%)$ patients who had increased lung CT scores were admitted to intensive care unit (ICU) whereas none of the patients with decreased or stable lung CT scores had ICU admission. One (5\%) patient in progressive group died while none of the patients in the non-progressive group died. 
Fig. 2 The flowchart of the study

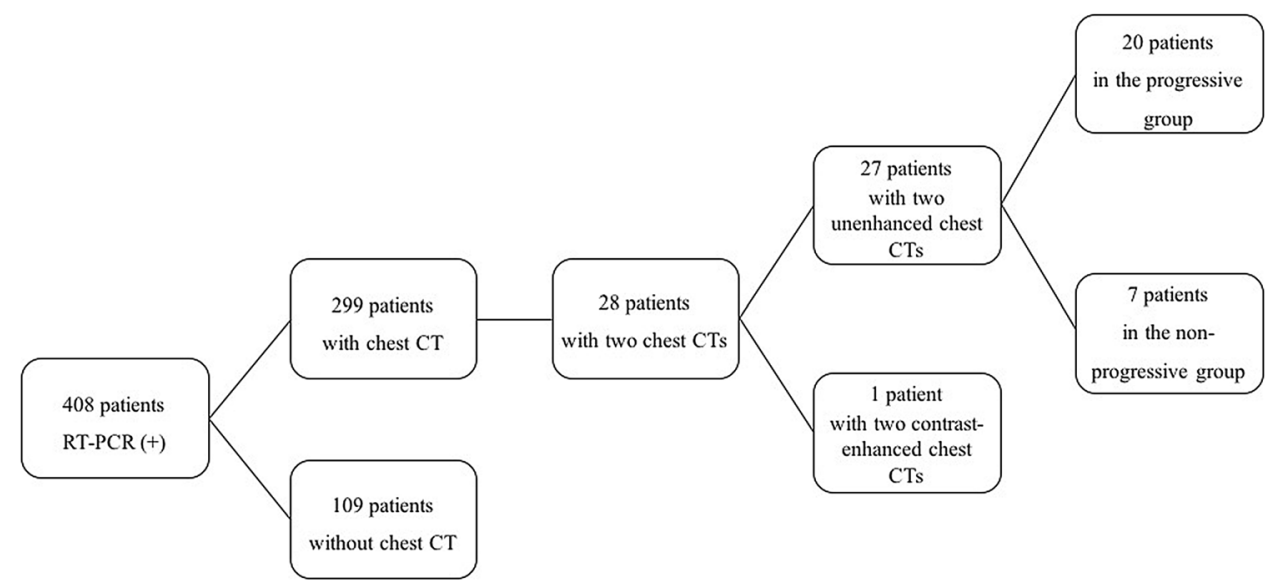

Table 1 Patient demographics and clinical characteristics of the two groups of COVID-19 patients

\begin{tabular}{llll}
\hline Parameter & $\begin{array}{l}\text { Non-progres- } \\
\text { sive group } \\
(n=7)\end{array}$ & $\begin{array}{l}\text { Progres- } \\
\text { sive group } \\
(n=20)\end{array}$ & $p$ \\
\hline Age & $41(29-65)$ & $57(23-81)$ & 0.653 \\
Sex & $4(57.1 \%)$ & $8(40 \%)$ & 0.662 \\
Male & $3(42.8 \%)$ & $12(60 \%)$ & \\
Female & $3(42.8 \%)$ & $11(55 \%)$ & \\
Comorbidities & $1(14.3 \%)$ & $9(45 \%)$ & 0.204 \\
Hypertension & $3(42.9 \%)$ & $2(10 \%)$ & 0.091 \\
Diabetes mellitus & $0(0)$ & $1(5 \%)$ & 1.000 \\
Chronic renal failure & $1(14.3 \%)$ & $1(5 \%)$ & 0.459 \\
Malignancy & & & \\
Treatment & $6(85.7 \%)$ & $18(90 \%)$ & 1.000 \\
Hydorxychloroquine & $4(57.1 \%)$ & $11(55 \%)$ & 1.000 \\
Azithromycin \pm or other & & & \\
$\quad$ antibiotics & $3(42.9 \%)$ & $7(35 \%)$ & 1.000 \\
Oseltamivir & $1(14.3 \%)$ & $9(45 \%)$ & 0.204 \\
Favipiravir & $0(0)$ & $6(30 \%)$ & 0.155 \\
LMWH & $5(0-17)$ & $12.5(0-29)$ & $\mathbf{0 . 0 3 5}$ \\
Length of hospital stay $($ day $)$ & $0(0)$ & $6(30 \%)$ & 0.155 \\
ICU admission & & & 1.000 \\
Survival & & $1(5 \%)$ & \\
Dead & $(100 \%)$ & $19(95 \%)$ & \\
Alive & & & \\
\hline & & & \\
\hline
\end{tabular}

Data are $n(\%)$ or median (minimum-maximum)

ICU intensive care unit, $L M W H$ low-molecular-weight heparin

Laboratory parameters of the patients obtained at the time corresponding to the dates of the two chest CTs are detailed in Table 2. By using Brunner and Langer method, it was found that changes of parameters obtained at the time of hospital admission and follow-up were different between the two groups of patients for the following tests; AST, ALT, creatinine, and CRP. $\Delta$ values for each variable (differences between the values that were obtained at the time of the first chest $\mathrm{CT}$ and the second chest $\mathrm{CT}$ ) were compared for the two groups of patients. Among these parameters, $\Delta$ ALT values were found to be statistically significantly different between the two groups $(p=0.03)$. Additionally, patients with elevated lung CT scores had a significant change in $\Delta$ ALT values $(p=0.02)$. No significant difference was found for $\Delta$ AST values between the two groups.

In the progressive group, 14 (70\%) patients and 18 (90\%) of patients had elevated CRP levels at hospital admission and follow-up, respectively. The comparison of the two time intervals for CRP was significantly different in the progressive group $(p=0.039)$.

There were statistically significant differences between the two groups of patients in terms of WBC, neutrophil, lymphocyte, monocyte, and platelet counts that were obtained at hospital admission $(p<0.05)$. ROC analysis was used to determine cut-off values of the laboratory parameters obtained at the time of the first chest $\mathrm{CT}$ to predict the changes in the lung CT scores. Patients with a WBC count $<6 \times 10^{3} / \mu \mathrm{L}$, neutrophil count $<3.3 \times 10^{3} / \mu \mathrm{L}$, lymphocyte count $<1.7 \times 10^{3} / \mu \mathrm{L}$, monocyte count $<0.55 \times 10^{3} /$ $\mu \mathrm{L}$, and platelet count $<230 \times 10^{3} / \mu \mathrm{L}$, which were obtained correspondingly at the time of the first chest CT, were predicted to have elevated lung CT scores in the consecutive scan (Table 3).

\section{L/S and CT scores}

The median time interval from the onset of symptoms of the disease to the first chest CT scan was 2 days (range 1-4 days). The median time interval between the first and second chest CT scans for the study population were 8 days (range 2-29 days). The median time interval between the first and second chest CT scans were 12 days (range 4-26) and 7.5 days (range 2-29) for the non-progressive group and progressive group, respectively. Table 4 shows lung CT scores, L/S, and liver densities on $\mathrm{CT}$ of the two groups of patients for 
Table 2 Laboratory characteristics of the two groups of patients with COVID-19

\begin{tabular}{|c|c|c|c|c|c|c|c|c|}
\hline \multirow{3}{*}{$\begin{array}{l}\text { Parameter } \\
\text { AST* }^{*} \text { Increased }(n, \%)\end{array}$} & \multicolumn{2}{|c|}{ Non-progressive group $(n=7)$} & \multicolumn{2}{|c|}{ Progressive group $(n=20)$} & \multirow{2}{*}{\multicolumn{2}{|c|}{$\begin{array}{l}\text { Between group } \\
\text { comparison }(p)\end{array}$}} & \multirow{2}{*}{\multicolumn{2}{|c|}{$\begin{array}{l}\text { Hospital } \\
\text { admission and } \\
\text { follow-up com- } \\
\text { parison }(p)\end{array}$}} \\
\hline & \multirow{2}{*}{$\begin{array}{l}\text { At hospital admission } \\
19(10-28)\end{array}$} & \multirow{2}{*}{$\begin{array}{l}\text { Follow-up } \\
17(12-20)\end{array}$} & \multirow{2}{*}{$\begin{array}{l}\text { At hospital admission } \\
18(7-51)\end{array}$} & \multirow{2}{*}{$\begin{array}{l}\text { Follow-up } \\
22(5-97)\end{array}$} & & & & \\
\hline & & & & & $0.825^{\mathrm{a}}$ & $0.071^{\mathrm{b}}$ & $0.149^{c}$ & $0.141^{\mathrm{d}}$ \\
\hline $\begin{array}{l}\text { ALT* }^{*} \\
\text { Increased }(n, \%)\end{array}$ & $\begin{array}{l}18(5-58) \\
2(28.6)\end{array}$ & $\begin{array}{l}19(6-50) \\
1(14.3)\end{array}$ & $\begin{array}{l}16(6-50) \\
1(5)\end{array}$ & $\begin{array}{l}29(9-127) \\
5(25)\end{array}$ & $0.471^{\mathrm{a}}$ & $\mathbf{0 . 0 3 0}^{\mathrm{b}}$ & $0.344^{\mathrm{c}}$ & $\mathbf{0 . 0 2 0}^{\mathrm{d}}$ \\
\hline $\begin{array}{l}\text { ALP } \\
\text { Increased }(n, \%)\end{array}$ & $\begin{array}{l}61(39-109) \\
1(14.3)\end{array}$ & $\begin{array}{l}60(39-248) \\
1(14.3)\end{array}$ & $\begin{array}{l}60(36-98) \\
0(0)\end{array}$ & $\begin{array}{l}55.5(30-124) \\
1(5)\end{array}$ & 0.725 & & 0.246 & \\
\hline $\begin{array}{l}\text { GGT } \\
\text { Increased }(n, \%)\end{array}$ & $\begin{array}{l}20.5(11-39) \\
1(14.3)\end{array}$ & $\begin{array}{l}21(7-63) \\
2(28.6)\end{array}$ & $\begin{array}{l}17.5(7-81) \\
2(10)\end{array}$ & $\begin{array}{l}24(10-177) \\
6(30)\end{array}$ & 0.950 & & 0.148 & \\
\hline $\begin{array}{l}\text { Total bilirubin } \\
\text { Increased }(n, \%)\end{array}$ & $\begin{array}{l}0.2(0.1-0.4) \\
0(0)\end{array}$ & $\begin{array}{l}0.3(0.1-0.4) \\
0(0)\end{array}$ & $\begin{array}{l}0.3(0.01-1.3) \\
1(5)\end{array}$ & $\begin{array}{l}0.4(0.2-1.2) \\
2(10)\end{array}$ & 0.063 & & 0.006 & \\
\hline $\begin{array}{l}\text { Creatinine* } \\
\text { Increased }(n, \%)\end{array}$ & $\begin{array}{l}0.7(0.4-0.9) \\
0(0)\end{array}$ & $\begin{array}{l}0.8(0.4-1) \\
0(0)\end{array}$ & $\begin{array}{l}0.8(0.1-3.7) \\
2(10)\end{array}$ & $\begin{array}{l}0.7(0.5-2.7) \\
1(5)\end{array}$ & $0.234^{\mathrm{a}}$ & $0.009^{b}$ & $0.027^{\mathrm{c}}$ & $0.098^{\mathrm{d}}$ \\
\hline $\begin{array}{l}\text { Urea } \\
\text { Increased }(n, \%)\end{array}$ & $\begin{array}{l}29(14-33) \\
0(0)\end{array}$ & $\begin{array}{l}25(13-34) \\
0(0)\end{array}$ & $\begin{array}{l}30(12-235) \\
2(10)\end{array}$ & $\begin{array}{l}27(16-221) \\
2(10)\end{array}$ & 0.376 & & 0.035 & \\
\hline $\begin{array}{l}\mathrm{CRP}^{*} \\
\text { Increased }(n, \%)\end{array}$ & $\begin{array}{l}4.4(0.3-135.6) \\
3(42.8)\end{array}$ & $\begin{array}{l}0.8(0.3-211) \\
1(14.3)\end{array}$ & $\begin{array}{l}12.6(0.5-310.9) \\
14(70)\end{array}$ & $\begin{array}{l}37.7(1-176) \\
18(90)\end{array}$ & $0.439^{\mathrm{a}}$ & $0.105^{\mathrm{b}}$ & $0.249^{c}$ & $\mathbf{0 . 0 3 9 ^ { d }}$ \\
\hline $\begin{array}{l}\text { LDH } \\
\text { Increased }(n, \%)\end{array}$ & $\begin{array}{l}194(132-384) \\
2(28.6)\end{array}$ & $\begin{array}{l}182(166-376) \\
3(42.8)\end{array}$ & $\begin{array}{l}204(138-300) \\
5(25)\end{array}$ & $\begin{array}{l}211(117-364) \\
7(35)\end{array}$ & 0.949 & & 0.700 & \\
\hline $\begin{array}{l}\text { D-dimer } \\
\text { Increased }(n, \%)\end{array}$ & $\begin{array}{l}275(169-1355) \\
2(28.6)\end{array}$ & $\begin{array}{l}248(168-1413) \\
3(42.8)\end{array}$ & $\begin{array}{l}647.5(169-1919) \\
11(55)\end{array}$ & $\begin{array}{l}643.5(169-2733) \\
8(40)\end{array}$ & 0.114 & & 0.856 & \\
\hline $\begin{array}{l}\text { WBC } \\
\text { Increased }(n, \%) \\
\text { Decreased }(n, \%)\end{array}$ & $\begin{array}{l}8.3(4.3-13.9) \\
1(14.3) \\
1(14.3)\end{array}$ & $\begin{array}{l}8.5(5.1-13.2) \\
1(14.3) \\
0(0)\end{array}$ & $\begin{array}{l}4.9(0.6-8.9) \\
0(0) \\
7(35)\end{array}$ & $\begin{array}{l}5.1(0.5-12.1) \\
1(5) \\
6(30)\end{array}$ & $\mathbf{0 . 0 0 0}^{\mathrm{e}}$ & & 0.088 & \\
\hline $\begin{array}{l}\text { Neutrophil } \\
\text { Increased }(n, \%) \\
\text { Decreased }(n, \%)\end{array}$ & $\begin{array}{l}4.7(2-7.6) \\
1(14.3) \\
0(0)\end{array}$ & $\begin{array}{l}5.3(2.4-10.3) \\
1(14.3) \\
0(0)\end{array}$ & $\begin{array}{l}3(0.4-6.7) \\
0(0) \\
5(25)\end{array}$ & $\begin{array}{l}3.3(0.3-9.7) \\
1(5) \\
3(15)\end{array}$ & $\mathbf{0 . 0 3 7 ^ { \mathrm { e } }}$ & & 0.208 & \\
\hline $\begin{array}{l}\text { Lymphocyte } \\
\text { Increased }(n, \%) \\
\text { Decreased }(n, \%)\end{array}$ & $\begin{array}{l}2.4(1.3-4.7) \\
2(28.6) \\
0(0)\end{array}$ & $\begin{array}{l}2.3(1.5-3.6) \\
0(0) \\
0(0)\end{array}$ & $\begin{array}{l}1.4(0.08-2.1) \\
0(0) \\
6(30)\end{array}$ & $\begin{array}{l}(0.1-2) \\
0(0) \\
4(20)\end{array}$ & $0.000^{\mathrm{e}}$ & & 0.777 & \\
\hline $\begin{array}{l}\text { Monocyte } \\
\text { Increased }(n, \%)\end{array}$ & $\begin{array}{l}0.9(0.3-1.3) \\
4(57.1)\end{array}$ & $\begin{array}{l}0.8(0.4-1) \\
2(28.6)\end{array}$ & $\begin{array}{l}0.5(0.1-0.9) \\
2(10)\end{array}$ & $\begin{array}{l}0.5(0.07-1) \\
2(10)\end{array}$ & $0.009^{\mathrm{e}}$ & & 0.731 & \\
\hline NLR & $1.6(0.8-5)$ & $2(0.9-6.1)$ & $2.2(1-4.8)$ & $2.7(0.9-14.9)$ & 0.267 & & 0.299 & \\
\hline $\begin{array}{l}\mathrm{Hb} \\
\text { Decreased }(n, \%)\end{array}$ & $\begin{array}{l}11.3(8.2-16.2) \\
3(42.8)\end{array}$ & $\begin{array}{l}11.5(7.4-16.1) \\
3(42.8)\end{array}$ & $\begin{array}{l}13.3(1.9-17) \\
3(15)\end{array}$ & $\begin{array}{l}12.7(4.5-16.4) \\
3(15)\end{array}$ & 0.475 & & 0.050 & \\
\hline $\begin{array}{l}\text { Platelet } \\
\text { Increased }(n, \%) \\
\text { Decreased }(n, \%)\end{array}$ & $\begin{array}{l}253(203-399) \\
0(0) \\
0(0)\end{array}$ & $\begin{array}{l}285(191-409) \\
0(0) \\
0(0)\end{array}$ & $\begin{array}{l}190(68-247) \\
0(0) \\
2(10)\end{array}$ & $\begin{array}{l}219(86-336) \\
0(0) \\
2(10)\end{array}$ & $\mathbf{0 . 0 0 0}^{\mathrm{e}}$ & & 0.084 & \\
\hline
\end{tabular}

A $\mathrm{p}$ value of $<0.05$ was considered to be statistically significant in bold

Data are median (minimum-maximum). ALP alkaline phosphatase (35-104 U/L), ALT alanine aminotransferase (normal limits, $<45 \mathrm{U} / \mathrm{L}$ ), $A S T$ aspartate amino transferase (normal limits, $<35 \mathrm{U} / \mathrm{L})$, creatinine $(0.6-1.1 \mathrm{mg} / \mathrm{dL}), C R P$ C-reactive protein $(0-5 \mathrm{mg} / \mathrm{L}), \mathrm{d}-\mathrm{dimer}(<550 \mu \mathrm{g} / \mathrm{L}$ FEU), GGT gamma-glutamyltransferase (normal limits, $<38 \mathrm{U} / \mathrm{L}$ ), $H b$ hemoglobin $(11.7-16 \mathrm{~g} / \mathrm{dL}$ ), $L D H$ lactate dehydrogenase (normal limits, $<225 \mathrm{IU} / \mathrm{L})$, lymphocyte count $\left(1-3.38 \times 10^{3} / \mu \mathrm{L}\right)$, monocyte count $\left(0-0.8 \times 10^{3} / \mu \mathrm{L}\right)$, neutrophil count $\left(2.02-7.46 \times 10^{3} / \mu \mathrm{L}\right), N L R$ neutrophil / lymphocyte ratio, platelet count $\left(150-450 \times 10^{3} / \mu \mathrm{L}\right)$ total bilirubin $(0.1-1 \mathrm{mg} / \mathrm{dL})$, urea $(10-50 \mathrm{mg} / \mathrm{dL}), W B C$ white blood cells $\left(4.5-11 \times 10^{3} / \mu \mathrm{L}\right)$

* Interactions were found for these variables. Interactions represent that the changes of laboratory parameters obtained at hospital admission and follow-up were different between the two groups

${ }^{\mathrm{a}}$ Comparison of the parameters between progressive and non-progressive groups at the time of hospital admission

${ }^{\mathrm{b}}$ Comparison of $\Delta$ parameters between the progressive and non-progressive groups

${ }^{\mathrm{c}}$ Comparison of differences of the parameters obtained at the time of follow-up and hospital admission in the non-progressive group

${ }^{\mathrm{d}}$ Comparison of differences of the parameters obtained at the time of follow-up and hospital admission in the progressive group

${ }^{\text {e}}$ Statistically significant difference was found between progressive and non-progressive groups in terms of laboratory parameters at hospital admission 
Table 3 Predictors at hospital admission for the progression of lung CT score

\begin{tabular}{|c|c|c|c|c|c|c|c|c|c|c|}
\hline \multirow[t]{2}{*}{ Parameter } & \multirow[t]{2}{*}{ Cut-off value ${ }^{\mathrm{a}}$} & \multirow[t]{2}{*}{ AUC } & \multicolumn{2}{|c|}{$\begin{array}{l}95 \% \text { confidence } \\
\text { interval }\end{array}$} & \multirow[t]{2}{*}{$\begin{array}{l}\text { Sensitiv- } \\
\text { ity }(\%)\end{array}$} & \multirow[t]{2}{*}{ Specificity (\%) } & \multirow[t]{2}{*}{ PPV (\%) } & \multirow[t]{2}{*}{ NPV (\%) } & \multirow[t]{2}{*}{ Std. Error } & \multirow[t]{2}{*}{$p$} \\
\hline & & & Lower & Upper & & & & & & \\
\hline WBC count & 6 & 0.850 & 0.651 & 1 & 85 & 85.7 & 94.4 & 66.7 & 0.102 & 0.007 \\
\hline Neutrophil count & 3.3 & 0.757 & 0.531 & 0.983 & 75 & 71.4 & 88.2 & 50 & 0.115 & 0.046 \\
\hline Lymphocyte count & 1.7 & 0.843 & 0.654 & 1 & 90 & 71.4 & 90.5 & 83.3 & 0.096 & 0.008 \\
\hline Monocyte count & 0.55 & 0.757 & 0.510 & 1 & 70 & 57.1 & 82.4 & 40 & 0.126 & 0.046 \\
\hline Platelet count & 230 & 0.929 & 0.813 & 1 & 95 & 85.7 & 95 & 85.7 & 0.059 & 0.001 \\
\hline
\end{tabular}

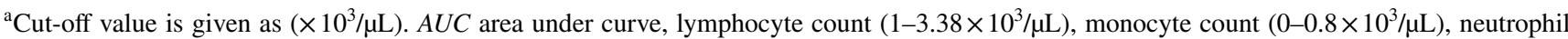
count $\left(2.02-7.46 \times 10^{3} / \mu \mathrm{L}\right), N P V$ negative predictive value, platelet count $\left(150-450 \times 10^{3} / \mu \mathrm{L}\right), P P V$ positive predictive value, $W B C$ white blood cells $\left(4.5-11 \times 10^{3} / \mu \mathrm{L}\right)$

Table 4 Liver-to-spleen ratio of the two groups of COVID-19 patients

\begin{tabular}{llllll}
\hline & \multicolumn{2}{l}{ Non-progressive group $(n=7)$} & & \multicolumn{2}{l}{ Progressive group $(n=20)$} \\
\cline { 2 - 3 } & At hospital admission & Follow-up & & At hospital admission & Follow-up \\
\hline CT score & $1(0-19)$ & $1(0-19)$ & & $6.5(0-14)$ & $12(5-24)$ \\
L/S & $1.21 \pm 0.29^{\mathrm{a}}$ & $1.25 \pm 0.29^{\mathrm{a}}$ & & $1.13 \pm 0.3^{\mathrm{b}}$ & $1.02 \pm 0.23^{\mathrm{b}}$ \\
Liver density (HU) & $52.52 \pm 12.4$ & $55.19 \pm 12.83$ & & $52.6 \pm 12.8$ & $49.87 \pm 11.09$ \\
& $56.67(30.33-65.33)$ & $58(38-73.67)$ & & $55.5(17.33-65)$ & $52(17.33-66)$ \\
\hline
\end{tabular}

Data are median (minimum-maximum) and mean \pm standard deviation. $L / S$ liver-to-spleen ratio

${ }^{a}$ In the non-progressive group, there was no significant difference between the comparison of L/S values that were obtained at hospital admission and follow-up $(p=0.465)$ (paired $t$-test)

${ }^{b}$ In the progressive group, there was a significant difference between the comparison of L/S values that were obtained at hospital admission and follow-up $(p=0.014)$ (paired $t$-test)

There was no significant difference of $\mathrm{L} / \mathrm{S}$ between the two groups at hospital admission $(p=0.547$ ) (independent samples $t$-test)

Follow-up L/S was significantly different between the two groups $(p=0.009)$ (covariance analysis)

The change between the baseline and follow-up L/S was statistically significant for the progressive group $(p=0.028)$ (independent samples t-test) the two time points. The mean $\mathrm{L} / \mathrm{S}$ of the progressive group was lower than that of the non-progressive group at hospital admission but there was no significant difference between the two groups $(p=0.547)$. However, L/S was found to be significantly different between the two groups of patients at follow-up ( $p=0.009)$ (Fig. 3). For the intragroup analysis, there was a significant change in $\mathrm{L} / \mathrm{S}$ in patients with increased lung CT score $(p=0.014)$. In the progressive group, as the median lung $\mathrm{CT}$ score was increased from 6.5 (range 0-14) to 12 (range 5-24) in two consecutive scans, the mean $\mathrm{L} / \mathrm{S}$ was decreased from $1.13 \pm 0.3$ to $1.02 \pm 0.23$. For the non-progressive group, L/S was elevated in the second CT scan, however the change in L/S was not statistically significant for the intragroup analysis $(p=0.465)$. The change between the baseline and follow-up L/S was found to be statistically significant for the progressive group $(p=0.028)$.

\section{L/S and laboratory findings}

For the whole group of patients, there was no significant correlation between L/S and ALT or AST that were obtained at hospital admission. However, negative correlations were found between L/S and both ALT and AST at followup $(r=-0.534, p=0.004$ for L/S and ALT; $r=-0.46$, $p=0.016$ for L/S and AST). As L/S decreased, both ALT and AST values increased.

An analysis was performed to evaluate the relationship between the therapies that were used for COVID-19 and liver function tests. When separate comparisons were performed between the patients who received hydroxychloroquine, azithromycin, other antibiotics, oseltamivir and who did not receive these agents, no significant differences of AST or ALT were found. However in patients who received favipiravir therapy, there was a significant change in both 
Fig. 3 66-year old woman with COVID-19. (a) CT lung score was 0 at hospital admission. (b) Liver-to-spleen ratio at hospital admission was calculated as 1.2. (c) CT lung score was 12 at follow-up CT scan which was obtained 10 days later. (d) Liver-to-spleen ratio at followup was calculated as 0.82
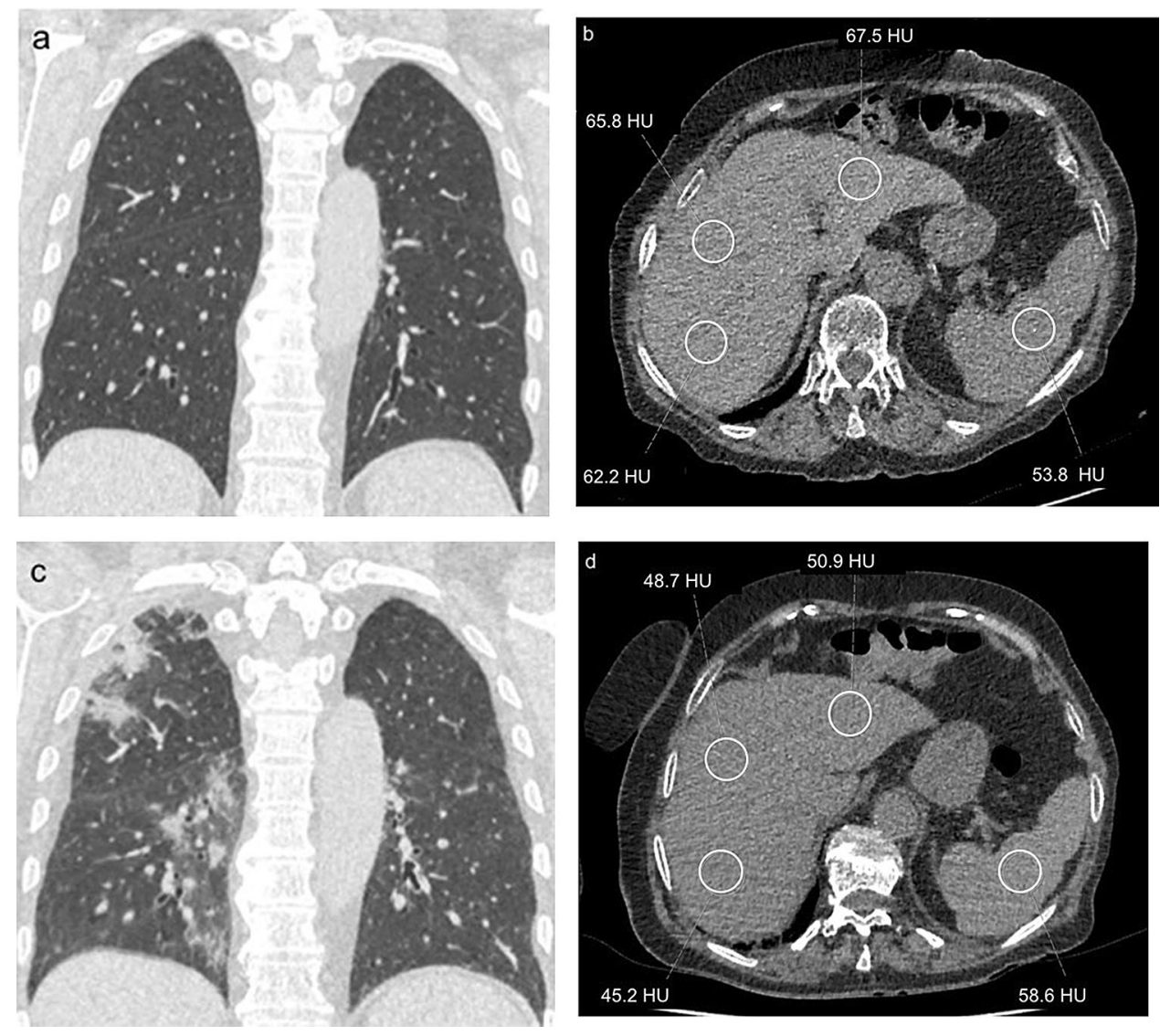

AST and ALT values $(p<0.05)$. Patients who had favipiravir treatment had increased AST and ALT levels at follow-up, however there was no significant change in L/S between the patients who received favipiravir and who did not.

\section{Discussion}

In this study, we aimed to monitor the changes in clinical, laboratory features, and L/S of COVID-19 patients during the course of disease. Many patients who are hospitalized due to COVID-19 get multiple chest CT scans depending on the clinical progression. There are a few series in the literature that have demonstrated how evolution of thoracic imaging findings happen $[2,11,20]$. In spite of the commonly observed chest imaging findings associated with COVID-19, reports of abdominal imaging findings are limited. A study has demonstrated that bowel involvement and cholestasis are the most common abdominal imaging findings in COVID-19 patients [23]. It has been reported that $16-53 \%$ of patients with COVID-19 have abnormal liver function tests during disease progression [24-26]. However, how the changes in liver parenchyma will be seen on imaging is not clear. It is known that changes of hepatic attenuation may be observed in some diffuse liver diseases and L/S is commonly used to assess the presence of liver fat $[14,15,17]$. In our study, we hypothesized the use of $\mathrm{L} / \mathrm{S}$ to evaluate the changes in hepatic attenuation between the two consecutive scans and investigated if it may correlate with abnormal liver function tests. We found that L/S at follow-up was significantly different between the progressive and non-progressive groups. As the lung CT scores increased, L/S tended to decrease on follow-up CTs. Similarly, in our study, liver function tests did not differ between the two groups of patients at hospital admission however, the increase in ALT values at follow-up was significant in patients with progressed lung CT scores $(p=0.02)$. Additionally, in patients with decreased L/S, ALT levels were elevated at follow-up $(p=0.004)$.

Although it is difficult to determine the underlying mechanism, our study demonstrated the changes in hepatic attenuation during the course of disease in COVID-19 patients. It has been proposed that liver injury in COVID-19 patients might be the direct result of the infection of liver cells [13]. The derangement of liver function is generally mild and other explanations for the liver damage such as immunemediated inflammation, cytokine storm, and pneumoniaassociated hypoxia are suggested [13, 27]. Abnormal liver function tests may also be observed in drug-induced hepatotoxicity with the use of hydroxychloroquine, azithromycin, and favipiravir in COVID-19 patients [28-30]. In our 
study, only in the group of patients who received favipiravir therapy had significantly elevated AST and ALT levels at follow-up, however, there was no change of L/S between the groups.

It has been suggested that hepatic steatosis might develop during the course of COVID-19 [31]. Histopathological examinations of the liver in COVID-19 patients have shown hepatic steatosis, mild lobular and portal inflammation [31, 32]. The decrease in L/S in the progressive group on followup that was identified in our study might be attributed to hepatic steatosis. In general, hepatic steatosis is most commonly associated with alcohol abuse and non-alcoholic fatty liver disease but it may be caused by various factors including viral hepatitis, ischemia, drug toxicity, and malnutrition [33]. Moreover, it has been demonstrated that SARS-CoV-2 infection may affect lipid metabolisms especially in patients with severe disease $[34,35]$. Thus, the causes of decreased $\mathrm{L} / \mathrm{S}$ in patients with progressive disease need to be further investigated.

Chest CT plays an important role in the diagnosis and evaluation of severity of COVID-19. In our study, patients with increased lung CT scores had a significantly longer hospital stay $(p=0.035)$. Similarly, Li et al. reported that the CT scores of the patients with critical disease were higher than those of the ordinary COVID-19 patients and lung CT scores can be used to accurately differentiate severe patients [12]. In our study, in patients with progressed lung CT scores, CRP levels were found to be significantly elevated at followup. It has been suggested that increased values of CRP may be positively correlated with lung involvement and disease severity [36].

Laboratory parameters such as WBC, absolute values of lymphocytes, platelets, albumin, total bilirubin, creatinine, blood urea nitrogen, CRP, interleukin-6, AST, LDH, myoglobin, troponin, procalcitonin, and d-dimer have been reported to be risk factors for critical or mortal COVID-19 cases [10, 37]. In our study, WBC, neutrophil, lymphocyte, monocyte, and platelet levels at hospital admission were significantly different between the progressive and non-progressive groups of patients. Among these parameters, platelet count $<230 \times 10^{3} / \mu \mathrm{L}$ predicted the progression of lung CT score with a sensitivity of $95 \%$ and specificity of $85.7 \%$.

Our study has several limitations including its retrospective design and small number of patients. Another limitation is that we did not evaluate the thoracic imaging characteristics of COVID-19. It has been reported that consolidation, linear opacities, crazy-paving pattern, bronchial wall thickening, and extrapulmonary lesions may be the imaging findings of severe COVID-19 patients. In our study, we evaluated the changes of L/S during the course of disease and used the lung CT scores to assess the extension and severity of the lung involvement in COVID-19 patients. Another limitation is the lack of contrast-enhanced liver imaging. Since multiple unenhanced chest CT scans were performed for COVID-19 patients, we wanted to investigate the changes in upper abdomen and focused on L/S. As L/S can be affected by the pre-existing liver diseases, we only evaluated the changes on two consecutive scans and excluded COVID-19 patients who had single CT scans. However, prospective studies with larger number of patients, using different imaging modalities are required to confirm and radiologically detect the changes in liver parenchyma, which could be multifactorial, in patients with COVID-19.

In conclusion, decrease in L/S may be observed in COVID-19 patients with elevated lung CT scores at followup. Additionally, WBC, neutrophil, lymphocyte, monocyte, and platelet counts that are obtained at hospital admission may predict the progression of disease.

\section{Compliance with ethical standards}

Conflict of interest All the authors declared that they have no conflicts of interest.

\section{References}

1. World Health Organization Timeline - COVID-19. Available at: https://www.who.int/news-room/detail/27-04-2020-who-timeline--covid-19 Accessed 6 May 2020.

2. Ai T, Yang Z, Hou H, et al (2020) Correlation of chest CT and RTPCR testing in coronavirus disease 2019 (COVID-19) in China: a report of 1014 cases. Radiology 200642. https://doi. org/10.1148/radiol.2020200642

3. Fang Y, Zhang H, Xie J et al (2020) Sensitivity of chest CT for COVID-19: comparison to RT-PCR. Radiology 200432. https:// doi.org/10.1148/radiol.2020200432

4. Xie X, Zhong Z, Zhao W, et al (2020) Chest CT for typical 2019nCoV pneumonia: relationship to negative RT-PCR testing. Radiology 200343. doi:https://doi.org/10.1148/radiol.2020200343

5. Li Y, Xia L (2020) Coronavirus disease 2019 (COVID-19): role of chest CT in diagnosis and management. AJR Am J Roentgenol 214:1280-1286. doi:https://doi.org/10.2214/AJR.20.22954

6. Huang C, Wang Y, Li X, et al (2020) Clinical features of patients infected with 2019 novel coronavirus in Wuhan, China. Lancet395:497-506. https://doi.org/10.1016/S0140-6736(20)30183-5

7. Wang D, Hu B, Hu C, et al (2020) Clinical characteristics of 138 hospitalized patients with 2019 novel coronavirus-infected pneumonia in Wuhan, China. JAMA 323:1061-1069. https://doi. org/10.1001/jama.2020.1585

8. Chen N, Zhou M, Dong X, et al (2020) Epidemiological and clinical characteristics of 99 cases of 2019 novel coronavirus pneumonia in Wuhan, China: a descriptive study. Lancet395:507-513. https://doi.org/10.1016/S0140-6736(20)30211-7

9. Zhou F, Yu T, Du R, et al (2020) Clinical course and risk factors for mortality of adult inpatients with COVID-19 in Wuhan, China: a retrospective cohort study. Lancet 395:1054-1062. https://doi. org/10.1016/S0140-6736(20)30566-3

10. Zheng Z, Peng F, Xu B, et al (2020) Risk factors of critical \& mortal COVID-19 cases: A systematic literature review and meta-analysis. J Infect S0163-4453(20)30234-6. doi:https://doi. org/10.1016/j.jinf.2020.04.021 
11. Wan S, Li M, Ye Z, et al (2020) CT manifestations and clinical characteristics of 1115 patients with Coronavirus disease 2019 (COVID-19): a systematic review and meta-analysis. Acad Radiol 27:910-921. https://doi.org/10.1016/j.acra.2020.04.033

12. Li K, Wu J, Wu F, et al (2020) The clinical and chest CT features associated with severe and critical COVID-19 pneumonia. Invest Radiol 55:327-331. doi:https://doi.org/10.1097/RLI.0000000000 000672

13. Zhang C, Shi L, Wang FS (2020) Liver injury in COVID-19: management and challenges. Lancet Gastroenterol Hepatol 5:428-430. https://doi.org/10.1016/S2468-1253(20)30057-1

14. Kodama Y, Ng CS, Wu TT et al (2007) Comparison of CT methods for determining the fat content of the liver. AJR Am J Roentgenol 188:1307-1312. https://doi.org/10.2214/AJR.06.0992

15. Ma X, Holalkere NS, Kambadakone R A, et al (2009) Imagingbased quantification of hepatic fat: methods and clinical applications. Radiographics 29:1253-1277. https://doi.org/10.1148/ rg. 295085186

16. Yasui S, Fujiwara K, Okitsu K, et al (2012) Importance of computed tomography imaging features for the diagnosis of autoimmune acute liver failure. Hepatol Res 42:42-50. https://doi. org/10.1111/j.1872-034X.2011.00892.x

17. Iwasaki M, Takada Y, Hayashi M, et al (2004) Noninvasive evaluation of graft steatosis in living donor liver transplantation. Transplantation 78:1501-1505. https://doi.org/10.1097/01.tp.00001 40499.23683.0d

18. COVID-19 treatment algorithm for adults. Available at: https:// covid19bilgi.saglik.gov.tr/depo/algoritmalar/COVID19 Accessed 11 May 2020.

19. Chang YC, Yu CJ, Chang SC, et al (2005) Pulmonary sequelae in convalescent patients after severe acute respiratory syndrome: evaluation with thin-section CT. Radiology 236:1067-1075. https ://doi.org/10.1148/radiol.2363040958

20. Pan F, Ye T, Sun $P$, et al (2020) Time course of lung changes on chest CT during recovery from 2019 novel coronavirus (COVID19) pneumonia. Radiology 295:715-721. https://doi.org/10.1148/ radiol.2020200370

21. Francone M, Iafrate F, Masci GM, et al (2020) Chest CT score in COVID-19 patients: correlation with disease severity and shortterm prognosis [published online ahead of print, $2020 \mathrm{Jul}$ 4]. Eur Radiol 1-10. https://doi.org/10.1007/s00330-020-07033-y

22. Zeb I, Li D, Nasir K, et al (2012) Computed tomography scans in the evaluation of fatty liver disease in a population based study: the multi-ethnic study of atherosclerosis. Acad Radiol 19:811-818. https://doi.org/10.1016/j.acra.2012.02.022

23. Bhayana R, Som A, Li MD, et al (2020) Abdominal imaging findings in COVID-19: preliminary observations. Radiology 201908. https://doi.org/10.1148/radiol.2020201908

24. Shi H, Han X, Jiang N, et al (2020) Radiological findings from 81 patients with COVID-19 pneumonia in Wuhan, China: a descriptive study. Lancet Infect Dis 20:425-434. https://doi.org/10.1016/ S1473-3099(20)30086-4

25. Xu XW, Wu XX, Jiang XG, et al (2020) Clinical findings in a group of patients infected with the 2019 novel coronavirus
(SARS-Cov-2) outside of Wuhan, China: retrospective case series. BMJ 368:m606. https://doi.org/10.1136/bmj.m606

26. Fan Z, Chen L, Li J, et al (2020) Clinical features of COVID19-related liver functional abnormality. Clin Gastroenterol Hepatol 18:1561-1566. https://doi.org/10.1016/j.cgh.2020.04.002

27. Bangash MN, Patel J, Parekh D (2020) COVID-19 and the liver: little cause for concern. Lancet Gastroenterol Hepatol 5:529-530. https://doi.org/10.1016/S2468-1253(20)30084-4

28. Falcão MB, Pamplona de Góes Cavalcanti L, Filgueiras Filho NM, et al (2020) Case report: hepatotoxicity associated with the use of hydroxychloroquine in a patient with novel coronavirus disease (COVID-19). Am J Trop Med Hyg 102:1214-1216. https://doi. org/10.4269/ajtmh.20-0276

29. Boeckmans J, Rodrigues RM, Demuyser T, et al (2020) COVID19 and drug-induced liver injury: a problem of plenty or a petty point? Arch Toxicol 94:1367-1369. doi:https://doi.org/10.1007/ s00204-020-02734-1

30. Cai Q, Yang M, Liu D, et al (2020) Experimental treatment with favipiravir for COVID-19: an open-label control study. Engineering (Beijing) 10.1016/j.eng.2020.03.007. https://doi.org/10.1016/j. eng.2020.03.007

31. Lagana SM, Kudose S, Iuga AC, et al (2020) Hepatic pathology in patients dying of COVID-19: a series of 40 cases including clinical, histologic, and virologic data. Mod Pathol 1-9. doi:https ://doi.org/10.1038/s41379-020-00649-x

32. Xu Z, Shi L, Wang Y, et al (2020) Pathological findings of COVID-19 associated with acute respiratory distress syndrome. Lancet Respir Med 8:420-422. https://doi.org/10.1016/ S2213-2600(20)30076-X

33. Milroy CM (2018) Fatty liver and the forensic pathologist. Acad Forensic Pathol 8:296-310. https://doi.org/10.1177/1925362118 782061

34. Wei X, Zeng W, Su J, et al (2020) Hypolipidemia is associated with the severity of COVID-19. J Clin Lipidol 14:297-304. https ://doi.org/10.1016/j.jacl.2020.04.008

35. Wang G, Zhang Q, Zhao X, et al (2020) Low high-density lipoprotein level is correlated with the severity of COVID-19 patients: an observational study. Lipids Health Dis 19:204. https://doi. org/10.1186/s12944-020-01382-9

36. Wang L (2020) C-reactive protein levels in the early stage of COVID-19. Med Mal Infect 50:332-334. https://doi.org/10.1016/j. medmal.2020.03.007

37. Ruan Q, Yang K, Wang W, et al (2020) Clinical predictors of mortality due to COVID-19 based on an analysis of data of 150 patients from Wuhan, China. Intensive Care Med 46:846-848. https://doi.org/10.1007/s00134-020-05991-x

Publisher's Note Springer Nature remains neutral with regard to jurisdictional claims in published maps and institutional affiliations. 